\title{
THE CONTRIBUTION OF AFRICAN LEAFY VEGETABLES (ALVs) \\ TO VITAMIN A INTAKE AND \\ THE INFLUENCE OF INCOME IN RURAL KENYA
}

\section{Oiye SO* ${ }^{1,2}$, Shiundu KM ${ }^{1}$ and RK Oniang' ${ }^{1}$}

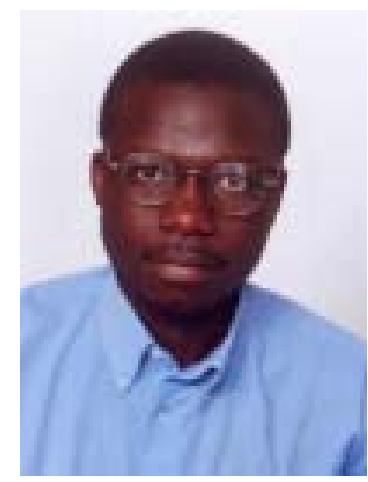

Oiye Shadrack

*Corresponding Author email: oiyeshad@gmail.com, oiyes@yahoo.com

${ }^{1}$ Rural Outreach Program, P. O Box 29086, Nairobi, Kenya

${ }^{2}$ Department of Food Technology and Nutrition, University of Nairobi, P. O Box 29053 


\begin{abstract}
Despite the increased recognition of African Leafy Vegetables (ALVs) as important source of vitamin A, there is still paucity of research highlighting on the vitamin A intake attributed to them. The level and the extent of contribution of ALVs could inform programming, monitoring and evaluation of vitamin A-related nutrition and development programs. The study aimed at investigating the level of contribution of ALVs to household vitamin A intake and the influence of household monthly income in a rural setting, through use of selected data from a cross-sectional vitamin A consumption survey in Butere-Mumias District, western Kenya. A multistage cluster sampling procedure was used to select 814 households considered for the survey. It was found that plant sources contributed about $43.1 \%$ of total household vitamin A intake. ALVs contributed $65.7 \%$ of vitamin A from plant sources and $32.7 \%$ of household vitamin A intake. Predominant ALV was the cowpea leaves which accounted for about $45 \%$ of vitamin A contributed by ALVs, $34 \%$ of the contribution of plant sources and $14.7 \%$ of household vitamin A intake. Although the influence of monthly income on the level of vitamin A from ALVs was not conclusive, there were some indications that lower intake from ALVs was positively correlated with lower incomes and vice versa. Income was weakly and negatively associated with household vitamin A intake ( $\mathrm{r}=-1.92,3.7 \%$ of variance explained), and the opposite was true for the proportion of income spent on food verses household vitamin A intake $(r=1.64$, $2.7 \%$ of variance explained). It was apparent that ALVs formed an important dietary source of vitamin A in rural households in western Kenya with cowpea leaves as a predominant contributor. In areas of similar environmental conditions, ALVs production, marketing and consumption should be promoted. There was no evidence that increase in income among the rural folk may likely improve ALVs consumption and vitamin A intake. It is thus recommended that development programs and policies consider ALVs as significant source of vitamin A, and that increments in incomes per se may not significantly influence household vitamin A intake and from ALVs.
\end{abstract}

Key words: African Leafy Vegetables, Vitamin A, Income

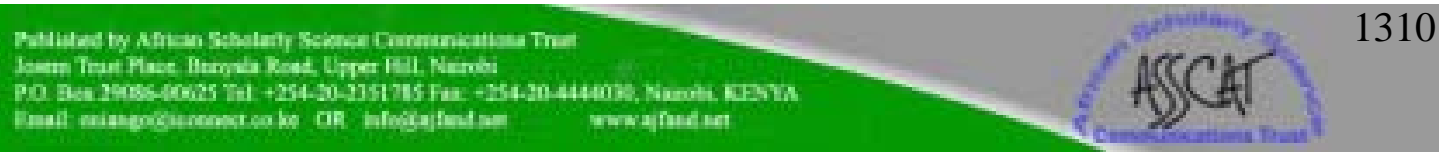




\section{INTRODUCTION}

Vitamin A deficiency is still a public health problem especially in sub-Sahara Africa and South-East Asia, effecting mostly young children and pregnant mothers in lowincome countries [1]. In Kenya, Vitamin A deficiency has been documented in 11 districts [2]. World Health Organization (WHO) has also listed Kenya among the 72 countries in the world suspected to have low serum retinol levels [3]. The past demographic surveys show Vitamin A deficiency nationally to be at all-time high at 76 percent [4]. The relationship between vitamin A consumption and blindness is currently well established. Supplementary trials have also revealed the association between vitamin A and reduced morbidity and mortality [5]. As a method to combat vitamin A deficiency, vitamin A supplementation began in Kenya several years ago and is continuing. However, there has been a realization that one of the most effective and sustainable way to overcome vitamin A deficiency is through food-based strategies, which, with time, are able to build into, and become part of the existing dietary systems [6]. Food fortification is often touted as the most promising short- to medium-term strategy for combating micronutrient deficiency [7]. However, even the smallest price increase attributed to fortification tends to discourage the poorest who also are the neediest in this case [8]. Further, despite the appealing nature of fortification, its progress has been slow [8]. Dietary diversification is one of foodbased intervention that is deemed feasible in Africa [9]. Though the main source of vitamin $A$ is the animal source foods, plant sources represent more than $80 \%$ of total food intake of vitamin A in sub-Saharan Africa because of their low-cost, high availability and diversity [9]. Fruits, roots, tubers and leafy vegetables are the main providers of provitamin A carotenoids. Due to their availability and affordability, green leafy vegetables are largely consumed by the poor populations, but their provitamin A activity has been proven to be less $(12 \mu \mathrm{g}$ of $\beta$-carotene for $1 \mu \mathrm{g}$ of retinol) [10] than previously assumed $(6 \mu \mathrm{g}$ of $\beta$-carotene for $1 \mu \mathrm{g}$ of retinol) [11]. It is now acknowledged that coloured fruits and cooked yellow tubers are much more efficiently converted to vitamin A than equal amounts of dark-green leafy vegetables [12]. The comparatively low pro-vitamin A activity in ALVs should not be a factor in diminishing the role of these crops in current and future efforts to address vitamin A deficiency. The critical issue is to broaden the strategy, to progressively include diverse plant materials that would synergize and subsequently, hasten the reduction of VAD globally.

In many rural communities in Africa, consumption of indigenous green African Leafy Vegetables (ALVs) is common, though decreasing as 'exotic' vegetables, which are more affordable, more available throughout the year, but relatively poor in provitamin A content gain currency. In the recent past, ALVs were associated with low-class people hence they were considered to be food for the poor. These misconceptions still linger in some places in Africa and will take time to change. Most ALVs are much superior to common 'exotic' or commercially produced vegetables in Kenya (kales and cabbages) in $\beta$-carotene and other vitamin and mineral contents. Increasing the consumption of ALVs and possibly substituting for kales and cabbages in Kenya can go a long way in improving vitamin A intake. Using this as the basis, there are a

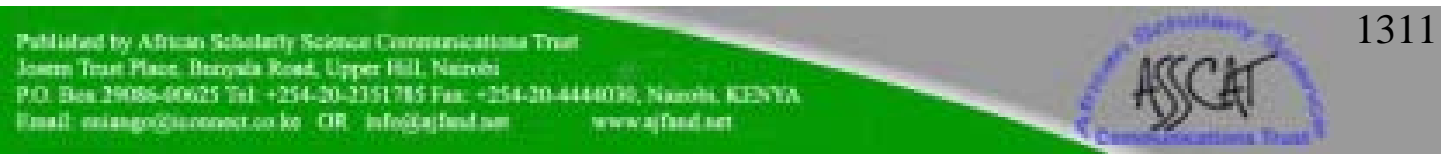


number of programs in Kenya that have attempted to increase the consumption of ALVs in the effort to increase micronutrient intake both in the rural and urban areas. In the high agricultural potential rural areas, promotion and support of production, post-harvest processing, marketing and consumption of ALVs has been encouraged. In the urban areas there is emphasis on dietary diversification and efforts to embrace traditional foods including ALVs in diets. This has mainly been to curb the rise of non-communicable diseases related to the urban dietary practices. Against these efforts, there is still paucity of demonstrated evidence on the contribution of ALVs to vitamin A supply - besides lack of evidence for the contribution of plant-based foods in general. As such, it has been difficult to evaluate the impact of or potential nutritional benefits of many rural-based programs which attempt to improve vitamin A intake through increased production, marketing and consumption of ALVs.

This paper thus utilized extracted data from a vitamin A survey conducted to estimate the contribution of African Leafy Vegetables to household vitamin A intake in Butere-Mumias district, Western Kenya. Some results from the same survey can be found in Shiundu et al. [8]. The paper also aimed to analyze the association between household vitamin A intake (and vitamin A from ALVs) and household economic status as indicated by household monthly income and proportion of income spent on food.

\section{METHODOLOGY}

\section{Sampling and sample size}

The study area (Butere-Mumias District) is in the Lake Region and experiences 2 rainy seasons: the short rains between August and November and the long rains between late February and June. Two divisions in the district were randomly selected as representative of divisions where the ALVs were being promoted (Butere) and where there was no promotion (Khwisero). Eight hundred and seventeen (402 in Butere division and 412 in Khwisero division) households with children 12-71 months were selected using a multistage cluster sampling procedure, the most popular and practical way of sampling the population at risk of vitamin A deficiency [13]. The 24hour recall was targeted on approximately $20 \%$ of the households (141 households after attrition due to data incoherence), randomly selected out of the 814 considered for the household survey. About 44 ALVs farmers (22 from each division) not involved the household survey were also randomly selected ( 2 from each village) and asked to cook selected vitamin A-rich foods from their farms for $\beta$-carotene analysis.

\section{General household survey and food frequency}

A food frequency checklist questionnaire adapted from Hellen Keller International (HKI) food frequency questionnaire was administered to the 814 households selected. The respondents were the mothers who were questioned on how often the households ate pre-listed foods in the past 7 days. Before administering the food frequency questionnaire, food items that are rich in vitamin A content and were available in the locality were identified through qualitative market surveys and group discussions. However, vitamin A rich foods in the HKI frequency list (compulsory ones) were

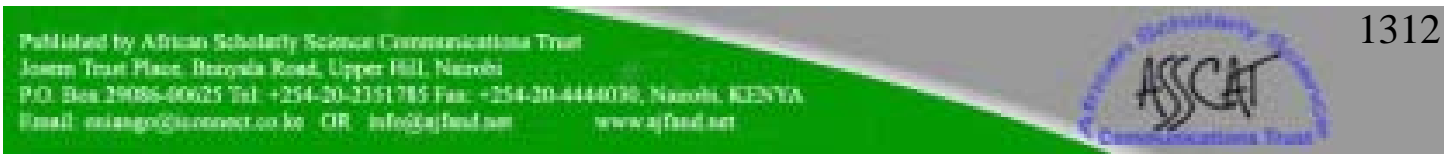


included in the food frequency questionnaire even if some of these foods were not commonly available locally.

\section{Twenty four-hour analysis}

Caregivers (mothers) were asked about their household food intake. All food consumed from getting up to going down to sleep were recorded in order to assess the amounts consumed accurately. To estimate the household vitamin A intake, food composition tables prepared by Sehmi (1993) were considered [14] except for the analyzed ALVs where laboratory results from $\beta$-carotene analysis were used. Retinol equivalents were calculated by dividing the $\beta$-carotene content by 12 ( $\beta$-caroteneretinol conversion rate of 12:1) as recommended by Institute of Medicine [10]. To standardize and estimate household vitamin A intake, total daily vitamin A consumed in the household was divided by the number of household members and presented in microgram Retinol Equivalents per person per day ( $\mu \mathrm{RE} / \mathrm{p} / \mathrm{d})$.

\section{Analysis of $\beta$-carotene content in foods}

Edible portions of plant foods commonly consumed in the area and rich in vitamin A as indicated by the results of household survey were analyzed for $\beta$-carotene content. Each farmer was instructed to harvest a particular crop from his/her respective farm and prepare (cook) the edible portions in the usual way known to them without any standard instructions given. For each division, it was ensured that one food item was prepared by 2 farmers. Thus for every food item, 4 samples were obtained (two from each division). They were transported in cool boxes immediately to Nairobi, about $400 \mathrm{~km}$ away for $\beta$-carotene analysis at the Nairobi University Food Laboratories. $\beta$ carotene content was analyzed using a High Performance Liquid Chromatography (HPLC). For each sample, the analysis was done in triplicates. The $\beta$-carotene content of the 4 separate samples were averaged to give the mean $\beta$-carotene content of respective food item. Food considered for analysis were kales (Brasica oleracea var acephala), cowpea leaves (Vigna unguiculata), African vegetable nightshade (Solanum spp), pumpkin leaves (Cucurbita maxima), jute mallow (Corchorus olitorius), Spider plant (Cleome gynadra), slenderleaf (Crotalarias ochroleuca), amaranths (Amaruthus lividus), orange-fleshed sweet potatoe (Ipomea butatus) and Ethiopian kales (Brassica carinata).

\section{Data analysis}

Means and percentages were calculated for socio-economic data, vitamin A content of food, food frequency and household vitamin A intake. For household vitamin A intake, student's t-test was also used to compare the vitamin A intakes for household with a monthly income below Kenya Shillings 2400 ( <US\$1 a day) and those above. Pearson correlation coefficient and linear regression analysis were used to determine the relationship or association between income and proportion of income spent on food and household vitamin A intake. Statistical Package for Social Scientists (SPSS) for windows version 11 was used for all statistical analyses, with a p-value $<0.05$ considered to indicate statistical significance where appropriate. Mean values were given $\pm \mathrm{SD}$ (Standard deviation). 


\section{RESULTS}

\section{Key socio-economic characteristics}

Table 1 depicts the socio-economic characteristics of the households interviewed in Butere and Khwisero divisions. On average, each household had about 5 members. The male gender was the predominant household head, averaged about 37 years old and mostly had attained primary school as the highest level of education. Own farming and casual labour were the leading sources of income for the households with the latter predominant in Khwisero division and former in Butere division. Butere division is comparatively a more sugarcane growing area than Khwisero and many families there depend on casual work in the sugarcane farms to supplement their subsistence farming. On average, about two-thirds of the total household income was spent on food. Among other food crops, about $86 \%$ of households grew ALVs on their farms and a high proportion of households grew the ALVs in Butere than in Khwisero divisions. On average in the two divisions, of the $43.8 \mathrm{~kg}$ of ALVs produced per household in the year preceding the survey, $26 \%$ was sold.

\section{Food frequency of selected vitamin A rich foods}

The HKI-modified 7-day food frequency used considered foods rich in vitamin A as presented in Table 2. ALVs (as a group) recorded the highest mean frequency, an indication that they were highly consumed (on average, 5 times a week) as compared to other foods listed. Almost all households $(98.8 \%)$ consumed it at least once a week. This could be an indication that ALVs are comparatively easily available and are important source of vitamin A in the study area. Other highly consumed vitamin A sources were kales, mangoes, eggs, papaya, sweet potatoes and fish, which were consumed at least once a week on average. Carrots, pumpkin fruit, butter, liver, codliver oil (Scots emulsion) were not highly consumed (less than once a week). Red palm oil was not consumed at all in the study area. Palm oil is rarely consumed in Kenya. Vitamin A rich foods highly consumed at least once a week by households were ALVs (98.8\%), kales (95.8\%), cooking oil and fat (75.3\%) and fish (82.8\%).

\section{Vitamin A content of ALVs}

Figure 1 depicts the vitamin A content of foods analyzed. Amaranths, African vegetable nightshade and spider plant were found to have high retinol equivalents after cooking. However, purple amaranths had the highest vitamin A content (518.33 $\mu \mathrm{gRE})$. Kales, cowpeas leaves, sunhemp, and Ethiopian kales had relatively medium vitamin content, while jute mallow and orange-fleshed sweet potato had least vitamin A content with the latter having the lowest of all the analyzed foods. The values presented in Figure 1 did not closely compare with those already published in Kenya $[12,13]$. The values presented in Figure 1 were used for computing vitamin A intake for ALVs. 


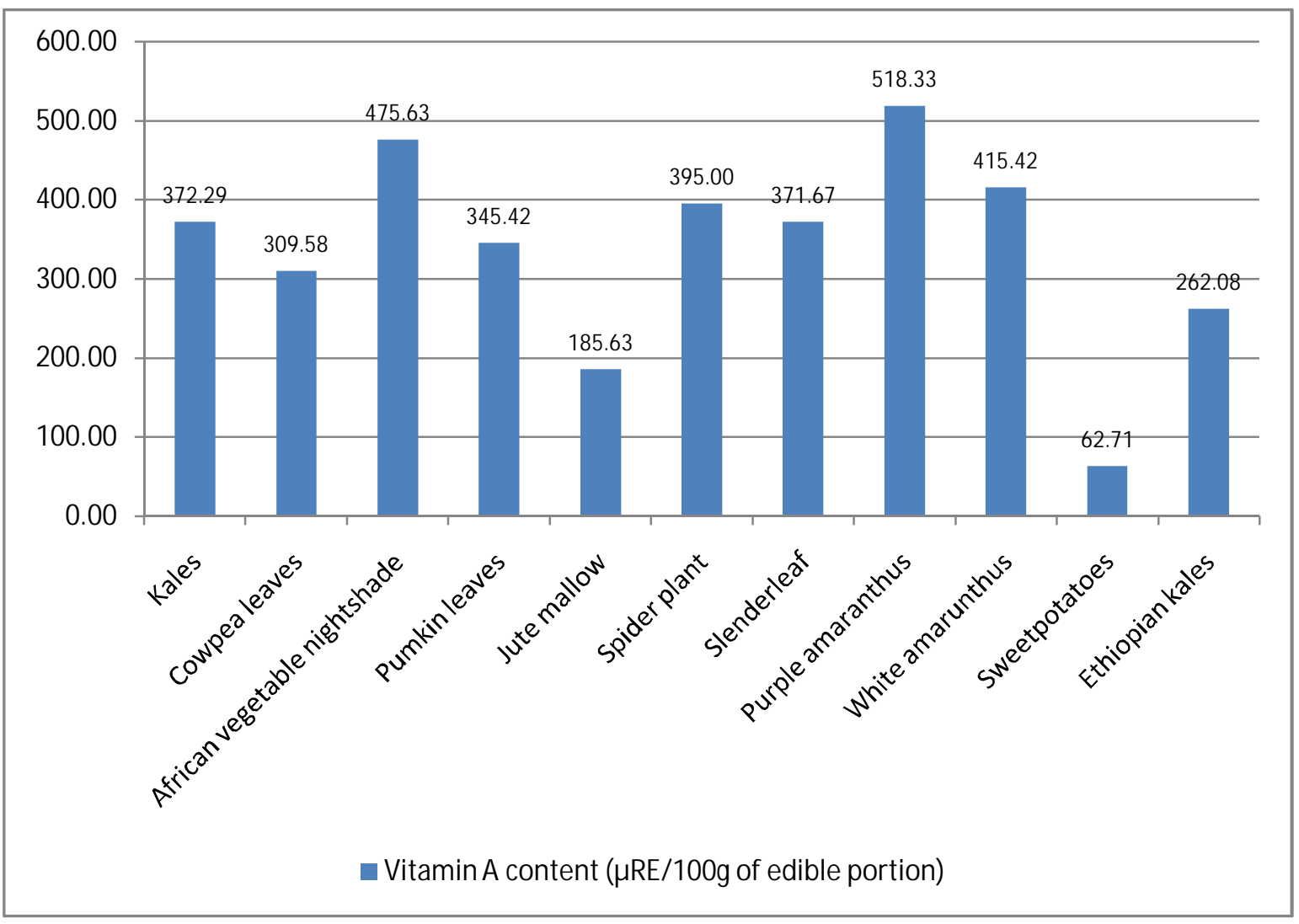

*The $\mathrm{Y}$ error bars are \pm SD

\section{Figure 1: Vitamin A composition of vitamin A rich plant foods}

\section{Contribution of ALVs to the vitamin A intake}

ALVs as a group contributed $239.3 \mu \mathrm{gRE} / \mathrm{p} / \mathrm{d}$ (Table 3), which accounted for $32.7 \%$ of the total vitamin A intake. There was no statistical significant difference in vitamin A intake from ALVs between households who earned less than and more than US\$1 a day ( $p>0.05)$ and this implies that income was a minor or insignificant determinant of vitamin A consumption from ALVs. However, as depicted by odds ratio (>1), vitamin A intake from ALVs below general average $(239.3 \mu \mathrm{gRE} / \mathrm{p} / \mathrm{d})$ was more likely in lowincome (<US\$1 a day) than in high income (>US\$1 a day) households. ALVs accounted for $65.7 \%$ for vitamin A from plant sources in total depicting that it is an important plant source of $\beta$-carotene. Plant source in total contributed an appreciable $43.1 \%$ of vitamin A household intake. About $44.8 \%$ of vitamin A intake that was contributed by ALVs was attributed to cowpea leaves consumption, which accounted for about $14.7 \%$ of total household vitamin A intake (Table 4). This represents the highest contribution of all the ALVs consumed and more than other foods groups save for other ALVs combined and vitamin A fortified cooking fats and oils. Slenderleaf and pumpkin leaves also seemed to be considerable contributors- each contributing about $5 \%$ of the total vitamin A intake per person, quite comparable to the 
contribution of kales and cabbages combined (other vegetables). Spider plant was the ALVs with least contribution to the household vitamin A intake.

Apart from ALVs, another significant, and evidently the highest contributor to vitamin A intake was the fats and oil. These were the fortified cooking fat and oils, and margarine (spread). They accounted for about 53.3\% of total vitamin A intake per adult person. It did not appear as if the higher the income, the higher the fats and oils consumption ( $\mathrm{p}>0.05)$. However, odds ratio indicated that households with incomes above US\$1 were likely to consume vitamin A amounts (from fats and oils) above the general average $(390 \mu \mathrm{gRE} / \mathrm{p} / \mathrm{d})$. Other foods that were likely to be consumed in households of higher incomes than lower, were eggs, milk and meat (Odds ration<1). These animal source foods are considered by rural dwellers as expensive or are associated with the affluent.

Following fats and oils, ALVs, other vegetables (kales and cabbages) and fruits (in that order) were found to be the next most important sources of vitamin A.

\section{Income and vitamin A intake}

The general trend was that the more a household earns per month, the less the vitamin A intake (Figure 2a). The converse (positive correlation) was true for the proportion of income spent on food - increase in income spent on food was associated with higher household vitamin A intake (Figure 2b). For the former case, the Pearson's coefficient of correlation was -1.92 with only $3.7 \%$ of the variance explained. Pearson's coefficient of correlation for the proportion spent on food was 1.64 with only $2.7 \%$ of the vitamin A intake variation explained. 


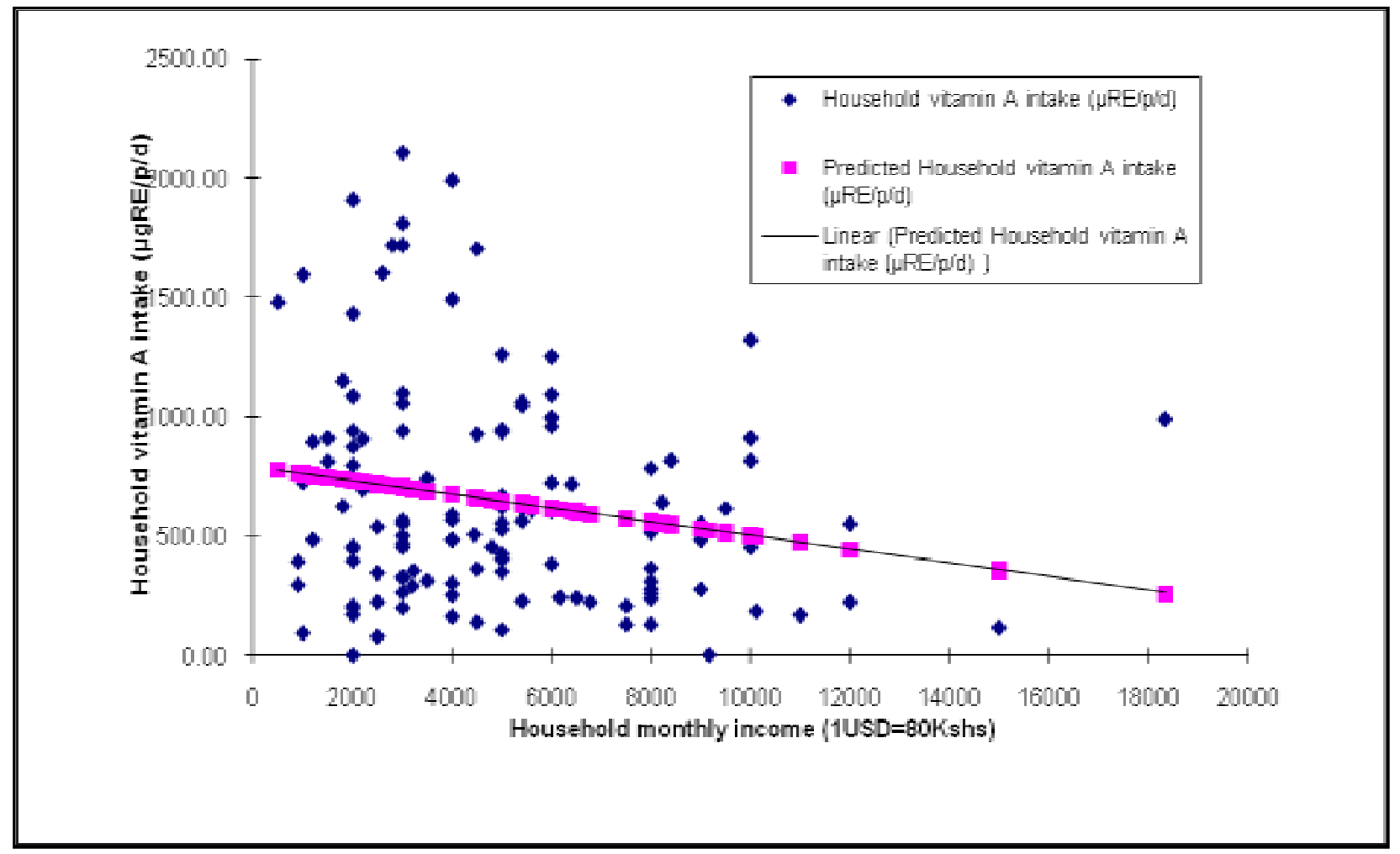

Figure 2a: Relationship between household monthly income and household vitamin A intake 


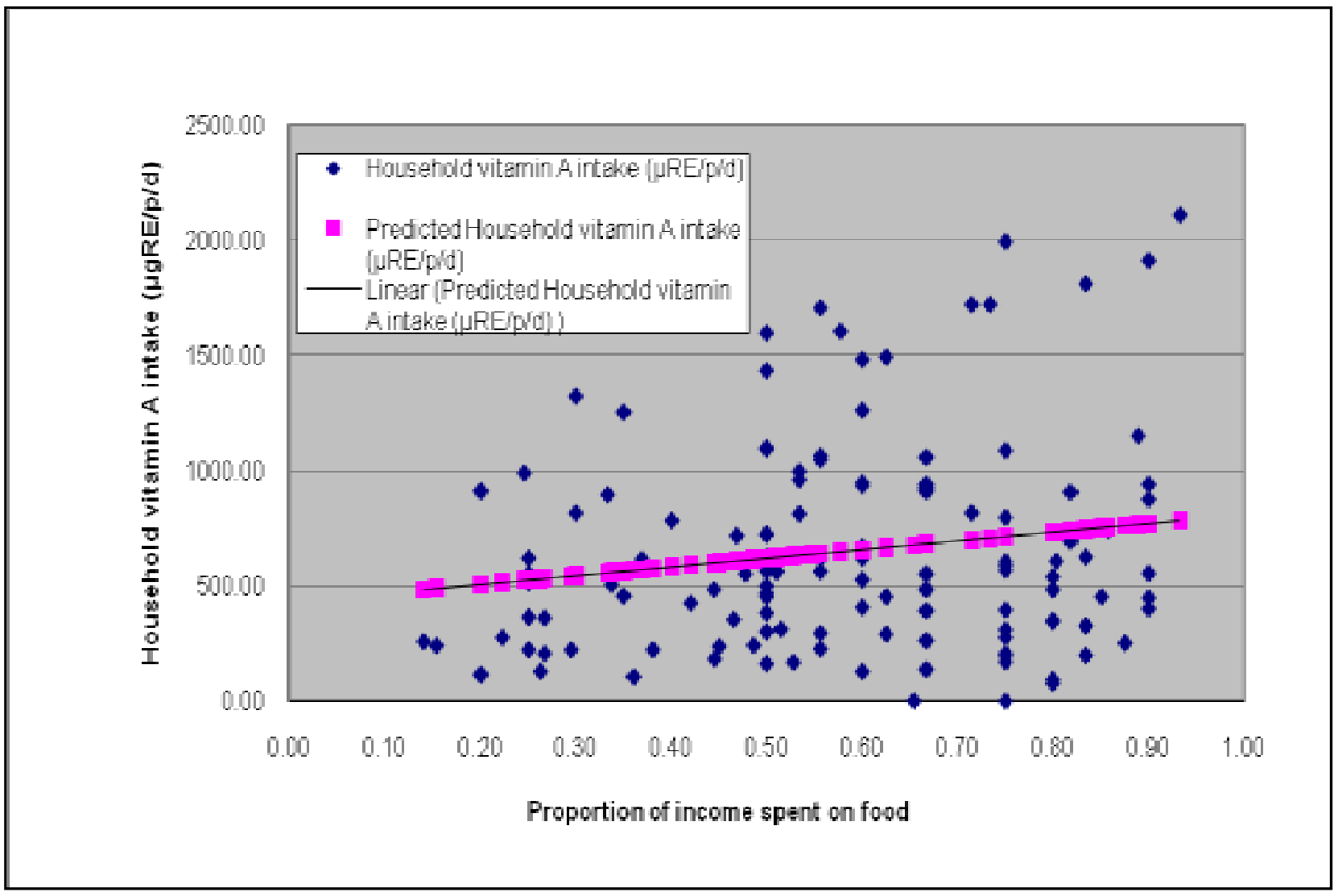

Figure 2b: Relationship between proportions of income spent on food and household vitamin A intake 


\section{DISCUSSIONS}

The sampling and preparation of foods analyzed was varied from the conventional approach of sampling and simulating preparation method in the laboratory prior $\beta$ carotene analysis. The samples were collected from farmers after home-based preparation. Uncontrolled preparation method prior to $\beta$-carotene analysis may partly explain the difference between the values reported here and those already published $[14,15]$. Other factors that can potentially explain the variations are the speciesspecific (genetic diversity, and stage maturation) and ecological factors such as soil and seasonality, among others [16].

The results are contrary to what has been stated about sub-Saharan Africa - that $80 \%$ of dietary intake of vitamin A comes from plant foods [9]. When combined, plant sources account for $43.13 \%$, roughly half of what may be expected $(80 \%)$. This however compares favorably with $48 \%$ contribution of fruits, nuts and vegetables (as a group) to vitamin A intake in United States diets [17]. It is also important to note that although the survey time cut across all seasons, seasonality was not factored in the analysis. Rainy seasons are normally associated with increased consumption of vegetables because they are highly available then. There could possibly be a marked different when the survey is done in dry season when the vegetables are expected to be scarce and expensive.

It was revealed that ALVs as a group are a major plant source of vitamin A, accounting for about a third of the total daily vitamin A intake and about two-thirds of the intake from plant foods. This does compare favorably with Faber et al. [18] who have reported $42-68 \%$ contribution of dark-green vegetables (not ALVs alone- ALVs inclusive) among 2-5 year old children KwaZulu Natal, South Africa. Of all the ALVs, cow pea leaves is the most important source of vitamin A. Out of the ALVs analyzed for $\beta$-carotene content, cowpea leaves have comparatively medium-level content of the pro-vitamin A. The reason why it is an important ALV (and overall a significant vitamin A source) could be because it is widely grown, consumed in large quantities and a preference for many in the study area. Consumption of ALVs in the study community can be traced back to many years and is a cultural dietary habit. In addition, there are development agencies that have been conducting promotional activities aimed at boosting ALVs production, marketing and consumption. Anecdotal data also depict that the community has moved from gathering wild ALVs to cultivating them -thanks to the efforts of supplying farmers with viable ALV seeds. Despite the marketing support initiatives in the study area, the community seems to be generally a net consumer, and not a net seller of ALVs; only about a quarter of the ALVs produced are sold in the markets.

The contribution of ALVs to vitamin A intakes of those earning more than US\$1 and those who earn less did not differ significantly. This could be an indication that the consumption of ALVs is a cultural practice, more influenced by availability and preference, and is less dependent on the household economic status. The scenario is however, not different from other food groups. Further analysis (of the odds of 'intake

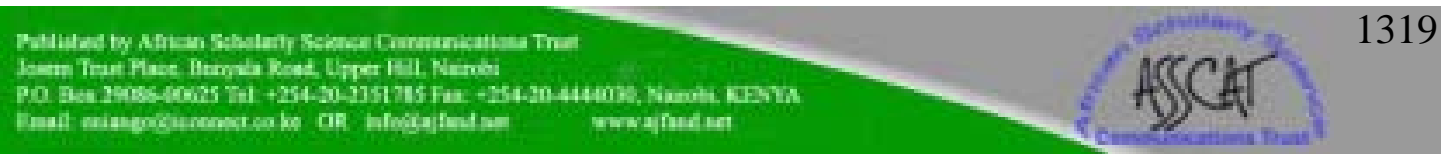


below average') however, brings out an interesting observation- vitamin A intake from ALVs below the general average computed is more likely in lower income groups than higher income groups. This hints that probably, there could be a relationship between the level of contribution of ALVs to vitamin A intake and household income. That is, the higher the household income, the higher likelihood of vitamin A intake from ALVs, and vice versa. The case is the same for fats and oils and animal source foods (meats and milk). The latter case is expected since animal source foods, fats and oils are largely bought, as opposed to ALVs, which are produced more for subsistence use than for commercial purposes.

It was noticed that the higher the income, the less the vitamin A intake. This correlation is weak and does not suggest significant influence on vitamin A intake. This is consistent with the earlier observation that income does not affect vitamin A intake from ALVs and other foods as well. One parameter that does show positive correlation with vitamin A intake is the proportion of income spent on food. The higher the proportion of income spent on food, the higher the vitamin A intake. The correlation however is also weak and not sufficient to indicate that improving the income-base and encouraging the use of more income to purchase food can lead to improvement in vitamin A intake.

\section{CONCLUSION AND RECOMMENDATION}

African Leafy Vegetables form an important dietary source of vitamin A, contributing about one-third of total vitamin A consumed in rural households in western Kenya. This also accounts for more than two-thirds of total contribution of plant-based foods. The most abundant and consumed ALVs, accounting for most of the dietary vitamin $\mathrm{A}$ is the cowpea leaves. Its contribution to daily vitamin A intake surpasses that of most food groups. In areas of similar environmental conditions, ALVs production, marketing and consumption should be promoted. There are inconclusive or unconvincing indications that the higher the income levels, the more the household vitamin A intake and intake from ALVs. Further, the proportion of income spent on food is positively but weakly correlated with total vitamin A intake. Nutrition and development programs and policies should consider ALVs as significant source of vitamin $\mathrm{A}$, and that increments in incomes per se may not significantly influence household vitamin A intake and from ALVs.

\section{ACKNOWLEDGMENTS}

The authors wish to thank Nutrition Third World, Belgium for funding this research work and the households in Butere-Mumias District, Kenya for their cooperation and willingness to provide information that was used in this study. 
Table 1: Socio-economic indicators of the study group

\begin{tabular}{|c|c|c|c|c|}
\hline Indicator & $\begin{array}{l}\text { Butere } \\
\mathrm{n}=\mathbf{4 0 2}\end{array}$ & $\begin{array}{c}\text { Khwisero } \\
n=412\end{array}$ & $\begin{array}{c}\text { Aggregate } \\
(n=814)\end{array}$ & P-value \\
\hline Average household size & 5.61 & 5.33 & 5.50 & 0.132 \\
\hline Household head ( $\%$ female) & 7.40 & 6.30 & 6.90 & \\
\hline Average age of the household head (years) & 38.54 & 36.04 & 37.28 & 0.002 \\
\hline $\begin{array}{l}\text { Most common highest level of education } \\
\text { of the household head }\end{array}$ & $\begin{array}{l}\text { Primary } \\
(60.20 \%)\end{array}$ & $\begin{array}{l}\text { Primary } \\
(56.80 \%)\end{array}$ & Primary $(58.60 \%)$ & \\
\hline Predominant source of income & $\begin{array}{l}\text { Casual labour } \\
(29.90 \%)\end{array}$ & $\begin{array}{l}\text { Subsistence } \\
(42.70 \%)\end{array}$ & $\begin{array}{l}\text { Subsistence } \\
\text { farming } \\
(35.60 \%)\end{array}$ & \\
\hline $\begin{array}{l}\text { Average household income per month in } \\
\text { Kshs (US\$) }\end{array}$ & $\begin{array}{c}3890 \\
(\sim \mathrm{US} \$ 48.60)\end{array}$ & $\begin{array}{c}4730 \\
(\sim \mathrm{US} \$ 59.12)\end{array}$ & $\begin{array}{c}4314 \\
(\sim \mathrm{US} \$ 54.00)\end{array}$ & 0.00001 \\
\hline $\begin{array}{l}\text { Income spent on food in Kshs (\% spent of } \\
\text { food) }\end{array}$ & $2543(65.37)$ & $2593(54.82)$ & $2568(59.52)$ & 0.653 \\
\hline $\begin{array}{l}\text { Percentage who grew ALVs in the } \\
\text { preceding year }\end{array}$ & 92.59 & 79.9 & 85.90 & \\
\hline $\begin{array}{l}\text { Percent who sold ALVs in the preceding } \\
\text { year }\end{array}$ & 38.30 & 9.50 & 54.60 & \\
\hline $\begin{array}{l}\text { Average ALVs production in the } \\
\text { preceding the survey year per household } \\
\text { in Kg }\end{array}$ & 64.38 & 23.70 & 43.87 & 0.000 \\
\hline $\begin{array}{l}\text { Average ALVs sold in the preceding year } \\
\text { preceding the survey per household ( } \% \\
\text { sold out of produced) }\end{array}$ & $18.55(28.8)$ & $4.31(18.86)$ & $11.37(25.91)$ & 0.000 \\
\hline
\end{tabular}

Table 2: 7-day food frequency vitamin A rich foods

\begin{tabular}{lcc}
\hline Food item & $\begin{array}{c}\text { Mean frequency }(\mathbf{n}=\mathbf{8 1 4}) \\
( \pm \mathrm{SD})\end{array}$ & $\begin{array}{c}\text { Percent } \\
\text { consumed } \\
\text { a week }\end{array}$ \\
\hline ALVs & $\begin{array}{c}\text { households food at least once } \\
\text { that }\end{array}$ \\
Kales & $5.22 \pm 1.72$ & 98.8 \\
Cooking oil and fat & $2.82 \pm 1.52$ & 95.8 \\
Fish & $1.85 \pm 1.80$ & 75.3 \\
Papaya & $1.72 \pm 1.35$ & 82.8 \\
Mango & $1.34 \pm 1.73$ & 65.1 \\
Egg & $1.22 \pm 1.43$ & 62.8 \\
Sweet potatoes & $1.16 \pm 1.26$ & 67.9 \\
Margarine (bread spread) & $1.06 \pm 1.24$ & 61 \\
Pumpkin fruit & $0.8 \pm 1.55$ & 33.5 \\
Cod liver & $0.34 \pm 0.70$ & 24 \\
Scots emulsion. emulsion & $0.25 \pm 1.17$ & 6.1 \\
Liver & $0.17 \pm 0.93$ & 5.1 \\
Carrots & $0.12 \pm 0.55$ & 7.5 \\
Butter & $0.12 \pm 0.48$ & 3.8 \\
Red palm oil & $0.05 \pm 0.33$ & 3.2 \\
\hline
\end{tabular}


Table 3: Household vitamin A intake from food groups

\begin{tabular}{|c|c|c|c|c|c|}
\hline \multirow{3}{*}{ Food group } & \multicolumn{5}{|c|}{ Vitamin A intake per person per day in $\mu \mathrm{g}$ Retinol Equivalents $(\mu \mathrm{g} \mathbf{R E} / \mathrm{p} / \mathrm{d}){ }^{\dagger}$} \\
\hline & \multicolumn{5}{|c|}{ Income levels } \\
\hline & $\begin{array}{c}<\text { US\$ } 1 \text { per day } \\
(n=37)\end{array}$ & $\begin{array}{c}>\text { US } \$ 1 \text { per day } \\
\quad(\mathrm{n}=109)\end{array}$ & P-value* & Average & Odds ratio $^{\S}$ \\
\hline $\begin{array}{l}\text { African } \\
\text { Vegetables }\end{array}$ & 230.50 & 241.95 & 0.870 & 239.32 & 1.108 \\
\hline $\begin{array}{l}\text { Other vegetables (kales } \\
\text { and cabbages) }\end{array}$ & 43.17 & 51.34 & 0.378 & 49.46 & 1.256 \\
\hline Fruits & 18.21 & 18.71 & 0.956 & 18.59 & 1.468 \\
\hline Roots and tubers & 6.38 & 8.32 & 0.925 & 7.88 & 0.686 \\
\hline $\begin{array}{l}\text { Cereals, pulses and } \\
\text { nuts }\end{array}$ & 0.11 & 0.21 & 0.309 & 0.19 & 2.171 \\
\hline Eggs & 0.00035 & 0.00012 & 0.611 & 0.00017 & 0.271 \\
\hline Fats and Oils & 351.78 & 401.33 & 0.351 & 389.95 & 0.650 \\
\hline Milk & 4.54 & 4.46 & 0.919 & 4.48 & 0.624 \\
\hline Fermented milk & 0.00 & 0.75 & 0.454 & 0.58 & 0 \\
\hline Meat $^{\ddagger}$ & 18.44 & 21.77 & 0.724 & 21.00 & 0.278 \\
\hline Total & 673.12 & 748.84 & & 731.45 & \\
\hline
\end{tabular}

Table 4: Household vitamin A intake from ALVs

\begin{tabular}{lccc}
\hline Vegetables & $\begin{array}{c}\text { Vitamin A intake }(\mu \mathrm{RE} \\
\text { per person })\end{array}$ & $\begin{array}{c}\text { As a \% of vitamin A } \\
\text { from ALVs }\end{array}$ & $\begin{array}{c}\text { \% contribution to total } \\
\text { vitamin A intake }\end{array}$ \\
\hline Jute mallow & 8.11 & 3.39 & 1.11 \\
African & 19.10 & 7.98 & 2.61 \\
vegetable & & & \\
nightshade & 3.96 & $\mathbf{1 . 6 5}$ & 0.54 \\
Spider plant & 38.10 & 15.92 & 5.21 \\
Slenderleaf & 38.77 & 16.20 & 5.30 \\
Pumpkin & & & \\
leaves & 107.20 & 44.80 & 14.66 \\
Cowpea leaves & 24.07 & 10.06 & 3.29 \\
Amaranths & & & \\
\hline
\end{tabular}




\section{REFERENCES}

1. WHO. Micronutrient deficiency combating vitamin A deficiency. World Health Organization website: www.who.org. 2001.

2. Daily Nation, 13th June 2001. Daily Nation news papers, Nairobi, Kenya.

3. Government of Kenya National Development Plan for the Period 1997-2001. Government Printer, 1996.

4. KDHS. (Kenya Demographic Health Survey) National Council for Population and Development, Central Bureau of Statistics, Ministry of Planning and National Development, 2003.

5. Nabutola $\mathbf{R}$ and $\mathbf{N}$ Penelop Inventory of current vitamin $A$ research and program activities related to child survival in developing countries. OMNI research. University States of International Development, 1999.

6. Chakravarity I Food-based strategies to control vitamin a deficiency. Food Nurtr Bull 2000:20:135-143.

7. Fieldler LJ, Smitz MF, Dupriez $\mathbf{O}$ and J Friedman Household income and expenditure surveys: A tool for accelerating the development of evidence-based fortification programs. Food Nurtr Bull 2008: 29: 306-319.

8. Shiundu KM, Oiye SO, Kumbe M and R Oniang'o Provision of vitamin A through utilization of local food materials in rural parts of western Kenya. AJFAND 2007: 7 (2):

9. Codjia G Food sources of vitamin and provitamin a specific to Africa: A FAO perspective. Food Nurtr Bull 2001: 22: 357-360.

10. Institute of Medicine (IOM) Dietary reference intakes for vitamin A, vitamin $\mathrm{K}$, arsenic, boron chromium, copper, iodine iron manganese molybdenum nickel, silicon, vanadium and zinc. Institute of Medicine. National Academy Press Washington D.C. 2001: 4-22.

11. Joint FAO/WHO Expert group Vitamin A deficiency and xerophthalmia. Tech Rep Ser. 1976: No 590. WHO, Geneva.

12. Miller M, Humprey J, Johnson E, Marinda, E, Meyer RB, Katz J Why do children become vitamin A deficient? J Nutr. 2002:132: 2867S-2880S.

13. Sommer A and JP West Vitamin A deficiency: Health survival and Vision. In Mclaren and Figgs. 2001. Sight and Life Guide book on vitamin A in health and diseases. $2^{\text {nd }}$ Edition. Basel. 1996. 
14. Sehmi JK National food composition Tables and Planning of satisfactory diets in Kenya. Ministry of Health/National Public Health Laboratory Services, Kenya, 1993.

15. Maundu PM, Ngungi GW and CHS Kabaye Traditional Food Plants of Kenya. Kenya Resource Centre for Indigenous Knowledge (KENRIK). National Museums of Kenya, Nairobi Kenya, 1999.

16. Booth SL, Johns TA, Kunhnlein HV Food sources of vitamin A and provitamin A. Food Nurtr Bull. 1992: 14: 3-33.

17. Adel AK, Penelop P and EL Gene Nutrition quality of fruits and nuts and their importance in Human health. www.ansinet.org/fulltext/pjbs/pjbs7813801384.pdf - 9 Jul 2005

18. Faber M, van Jaarsveld $\mathbf{P J}$ and $\mathbf{R}$ Laubscher The contribution of dark-green leafy vegetables to total nutrient intake of two- to five-year-old children in a rural setting. Water SA. 2007: 33: 407-412. 